\title{
Classification of Automatic Controllers Diagrams
}

\author{
Sviatoslav Klos, Roman Fedoryshyn, Volodymyr Savytskyi, \\ Yevhen Pistun \& Fedir Matiko
}
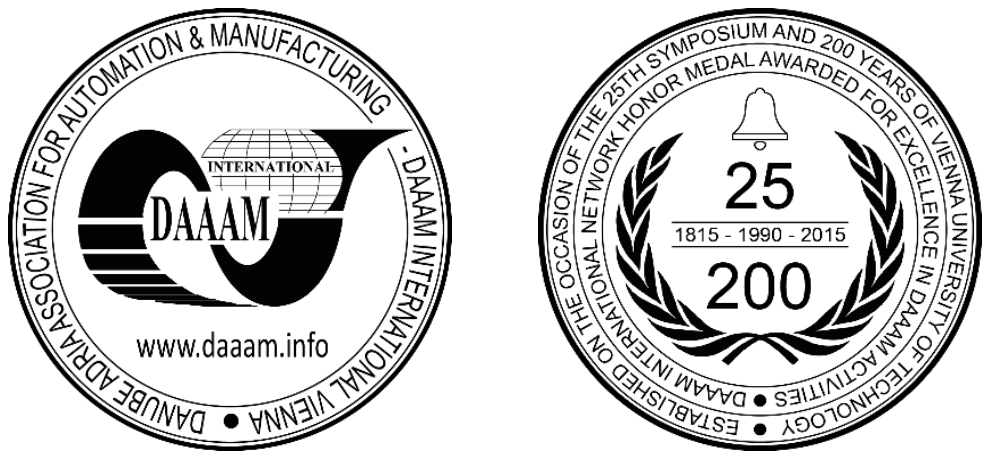

This Publication has to be referred as: Klos, S[viatoslav]; Fedoryshyn, R[oman]; Savytskyi, V[olodymyr]; Pistun, Y [evhen] \& Matiko, F[edir] (2017). Classification of Automatic Controllers Diagrams, Proceedings of the 28th DAAAM International Symposium, pp.0967-0973, B. Katalinic (Ed.), Published by DAAAM International, ISBN 978-3-90273411-2, ISSN 1726-9679, Vienna, Austria

DOI: $10.2507 / 28$ th.daaam.proceedings.134

\begin{abstract}
The analysis of the existing classifications of automatic controllers being applied in the industrial automation systems is presented in the paper. The main classification features in the existing classifications of automatic controllers are as follows: purpose, principle of operation, construction, type of energy being used, type of controlling action etc. A new classification of automatic controllers diagrams with control channels is proposed. According to this classification the control channel is considered as a part of the control loop consisting of an automatic controller and an intermediate element between the controller and the controlled plant. It is proposed to classify the automatic controllers diagrams on the basis of the following three features: type of control law, type of controller output signal and type of controlling action at the input of the controlled plant. The new classification is presented in a graphical and a table form. Each diagram is analyzed in details. The new classification provides exact demonstration and clear understanding of the place of switch, continuous and step controllers among other controllers. The classification also provides the possibility to obtain new types of diagrams of automatic controllers with the control channels. These diagrams can be implemented in PLCs by programming.
\end{abstract}

Keywords: automatic controller; diagram; classification; industrial automation; control law; output signal

\section{Introduction}

The main field of automatic control instruments application is technological processes and objects. These instruments may consist of individual control devices or programmable logic controllers (PLCs). Automatic regulation technique is the most important part of a traditional system of automatic control and automation. And the automatic regulation itself is an action destined at maintaining the controlled parameter at a set value.

Nowadays automated control systems are being more and more widely applied. These are human machine systems providing automatic acquisition and processing of data needed for optimization of the control process. Optimization here means choosing such a way of control at which the extreme value of the control criterion is reached.

Automation is still one of the main tasks to be accomplished for industrial production and for social life. As time goes by, automation becomes a wider concept which includes some new tasks of its scientific and engineering progress, i.e. computerization, robotics and other specialized fields of science. 
However, the main purpose of automation remains unchanged - it is making easier or complete replacement of human physical and brain work by means of automation instruments.

There is no field of industry where there would be no need to apply the automated systems for technological processes control. The main advantages of the automated control systems application are reduction (or even elimination) of the so called human factor influence on the technological process, minimization of raw materials consumption, improvement of quality of the output product and significant improvement of production efficiency. The main functions of such systems are automatic control, regulation, monitoring, data acquisition, exchange and storage, alarming, automatic protection and blocking as well as generating the curves and reports.

Automation engineers often meet the problem of choosing the instruments for solving the automation problems. There is one more important problem to be solved by the engineers in order to control the technological process - the problem of choosing the structure of the automatic controller (control law) and defining the numerical values of its tuning parameters. This problem can be solved on the basis of recommendations given in the specialized literature and in the technical documentation. To simplify solving of this problem, the classifications of automatic controllers were developed by various authors.

The goal of this work is to analyze the existing classifications of automatic controllers and to present the new developed classification of automatic controllers diagrams with the control channels.

\section{Analysis of the existing classifications of automatic controllers}

There are various classifications of automatic controllers in literature and electronic resources. Classifications of the following authors are known: Klyuyev A. S., Sharkov A. A., Kazakov A. V. and other.

Automatic controllers are classified by Klyuyev A. S. [1] on the basis of the following features: purpose of the controller, principle of operation, construction, type of energy being used and type of control law.

Based on the type of the controlled parameter the automatic controllers are divided into temperature controllers, pressure controllers, level controllers, flow rate controllers etc.

Based on the construction features the automatic controllers are divided into instrument controllers, device controllers, aggregate (unit) controllers and module (element) controllers. An instrument controller consists of the controller and the sensor (primary transducer). Instrument controllers operate independently (in parallel) to the other measurement instruments for a given technological parameter.

A device controller consists of the controller and the secondary transducer. There is no sensor (primary transducer) in the device controller.

The aggregate (unit) controllers consist of individual units with a specific function of each unit. The input and output signals of the units are uniform which provides the possibility of designing the controllers for various functional purposes.

The module (element) controllers consist of individual modules (elements) that accomplish simple operations. The input and output signals of the modules are uniform which provides the possibility of designing the controllers for various functional purposes (like in unit controllers).

Based on the source of energy being used the automatic controllers are divided into the direct action controllers and the indirect action controllers. In the direct action controllers part of the energy is taken from the controlled plant during measurement of the controlled value. This energy is used for controller operation and its action on the actuator. Thus, there is no external energy supply to the automatic system "controlled plant - automatic controller".

In the indirect action controllers the additional sources of energy are used to provide the controller operation and its action on the actuator.

Depending on the type of energy being used the indirect action controllers are divided into electric (electromechanical, electronic), pneumatic, hydraulic and combined (electro-pneumatic, electro-hydraulic etc.) controllers. The choice of the controller from the point of view of the type of energy being used is defined by the nature of the controlled plant and by the peculiarities of the automatic system.

Based on the type of the control law the automatic controllers are divided into controllers with linear and nonlinear control law. Switch controllers (two-point switch and three-point switch controllers) are the examples of the controllers with nonlinear control law.

According to Sharkov A. A. [2] the electric controllers being applied in the industry are divided into the following two types:

- device controllers consisting of the measurement devices with the built-in electric regulation devices for proportional or switch regulation;

- apparatus controllers consisting of autonomous control instruments which receive signals from the automatic sensors, implement a definite control law and transmit the controlling action signals to the actuators.

Classification of automatic controllers based on the purpose, principle of operation, construction, type of energy being used, type of controlling action etc. is given in [3]. This classification is presented as a diagram in Fig. 1.

Classification of automatic controllers based on a number of features is presented in [4] (Kazakov A. V.). This classification is similar to the one presented in [1]. However there is one more classification feature in [4], i.e. type of controlling action. Based on the type of the controlling action the controllers are divided into continuous and discrete controllers. The continuous controllers permanently act on the controlled plant during the control process. 
The discrete controllers act on the controlled plant only at definite moments of time or at reaching some definite values by the controlled parameter. The most simple and the most widespread type of a discrete controller is the switch controller.

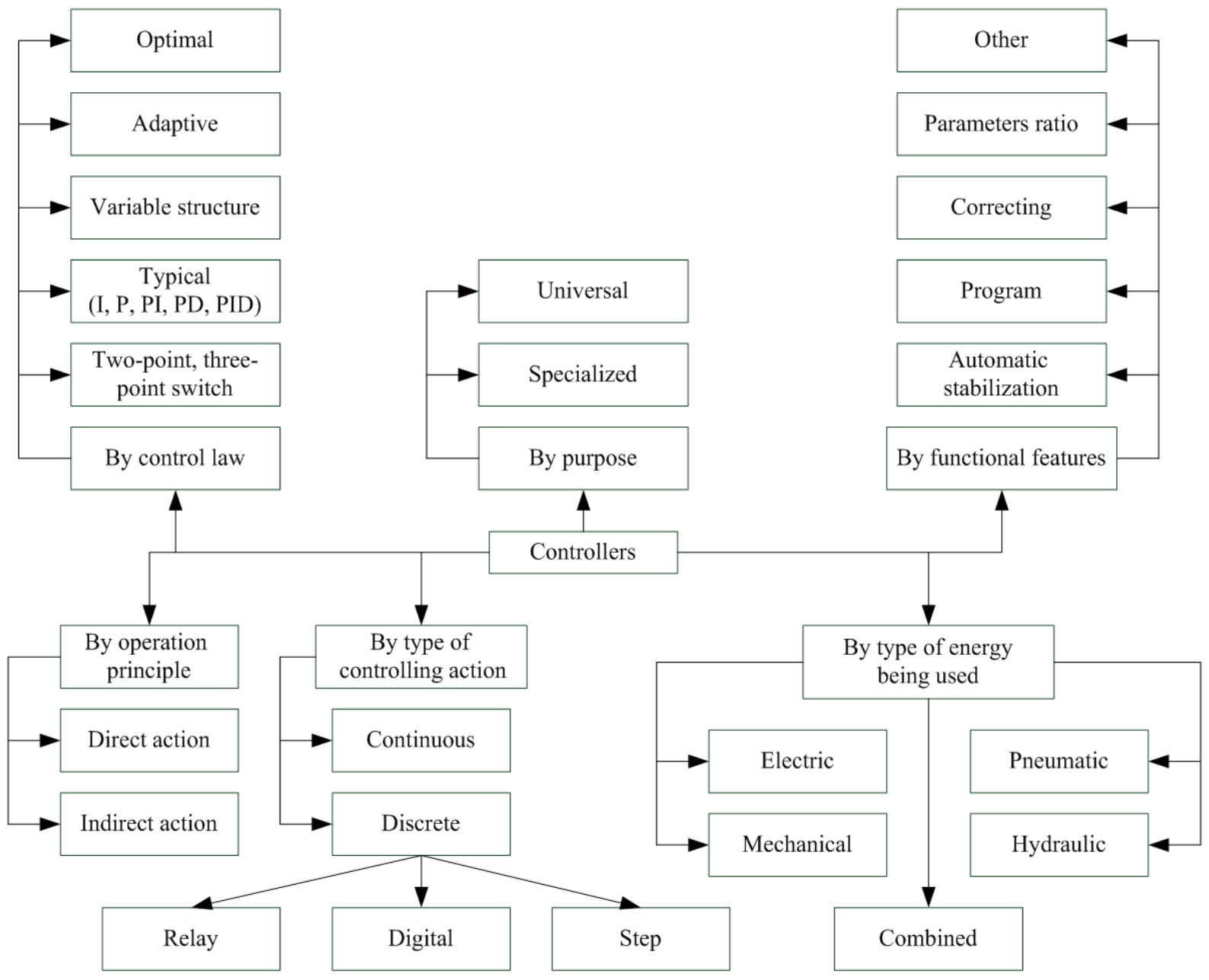

Fig. 1. Classification of automatic controllers according to [3]

One of the most important features for classification is the characteristics of the controller, i.e. the functional relation between the displacement of the valve and the deviation of the controlled parameter. The characteristics of the controller like of any other element in the automatic control loop (ACL) can be linear or non-linear [4].

Based on the type of the characteristics the controllers are divided into I-controllers (non-static), P-controllers (static), PI-controllers (isodromic) as well as controllers with differentiation, i.e. PD-controllers and PID-controllers [4].

The term "control law" came to the control systems theory from the classical theory. The "law" implies the mathematical relation based on which the controlling instrument would act on the controlled plant in case if it (instrument) possessed no inertia. Thus the "law" is an idealized algorithm of control. The actual algorithm of control would be quite different from the "law" due to the dynamics in the controlling instrument. However, since the inertia of most of the industrial controllers is small enough in comparison to the inertia of the controlled plant, the algorithm of control in the controllers is close to the "law" and this term is widely used. These laws are called typical and they are implemented by the controllers [3].

\section{New classification of automatic controllers diagrams}

Based on the accomplished review and analysis of the existing classifications of automatic controllers it was defined that there are a number of features for classifying the controllers (purpose of the controller, principle of operation, construction, type of energy being used, type of controlling action etc). However, little attention is paid to putting in order and classifying the diagrams implemented in the automatic controllers.

For better understanding of the distinction between the switch, continuous and step controllers as well as for understanding the place of these controllers among other controllers a new classification of automatic controllers diagrams with the control channels is proposed. 
According to the new classification the control channel is considered as a part of the automatic control loop consisting of an automatic controller (AC) and an intermediate element (IE) between the controller and a controlled plant (CP), see Fig. 2.

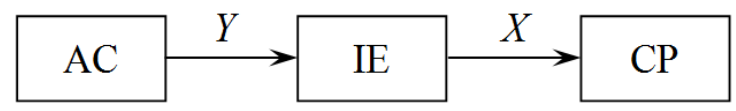

Fig. 2. Structure of the control channel: $Y$ is automatic controller output signal; $X$ is controlled plant input signal (controlling action)

The diagrams of automatic controllers with control channels are classified based on the following three features:

- type of control law;

- type of automatic controller output signal;

- type of controlling action on the controlled plant.

The control law implemented in an automatic controller can be of the following two types: continuous and switch. PID control law with its subtypes (i.e. P, I, PI, PD, ID) belongs to the continuous control law. The switch control law can be implemented by a two-point switch or a three-point switch.

The automatic controller output signal can be analog or impulse. And the controlling action on the controlled plant can also be analog or impulse.

The developed classification of automatic controllers diagrams with control channels is presented in Fig. 3. Conventional numbering of the automatic controllers diagrams with control channels from 1 to 8 is introduced.

The peculiarity of the developed classification is that the classification features are located in a hierarchical manner (see Fig. 3). Different types of controlling action on the controlled plant are considered for different types of controller output signal. And different types of controller output signal are considered for different types of control law. All possible combinations between the types of the control law, types of the controller output signal and types of the controlling action on the controlled plant are considered in the developed classification with taking into account the hierarchy of the classification features.

The diagrams of automatic controllers with control channels (diagrams $1-8$ ) according to the developed classification are presented in Fig. $4-11$. The description and analysis of these diagrams is made with respect to a thermal controlled plant (electric oven with air flow through it). Air temperature in the oven is the controlled parameter. Electric power at the input of the oven is the controlling action on the controlled plant. The detailed description of this controlled plant is presented in [5].

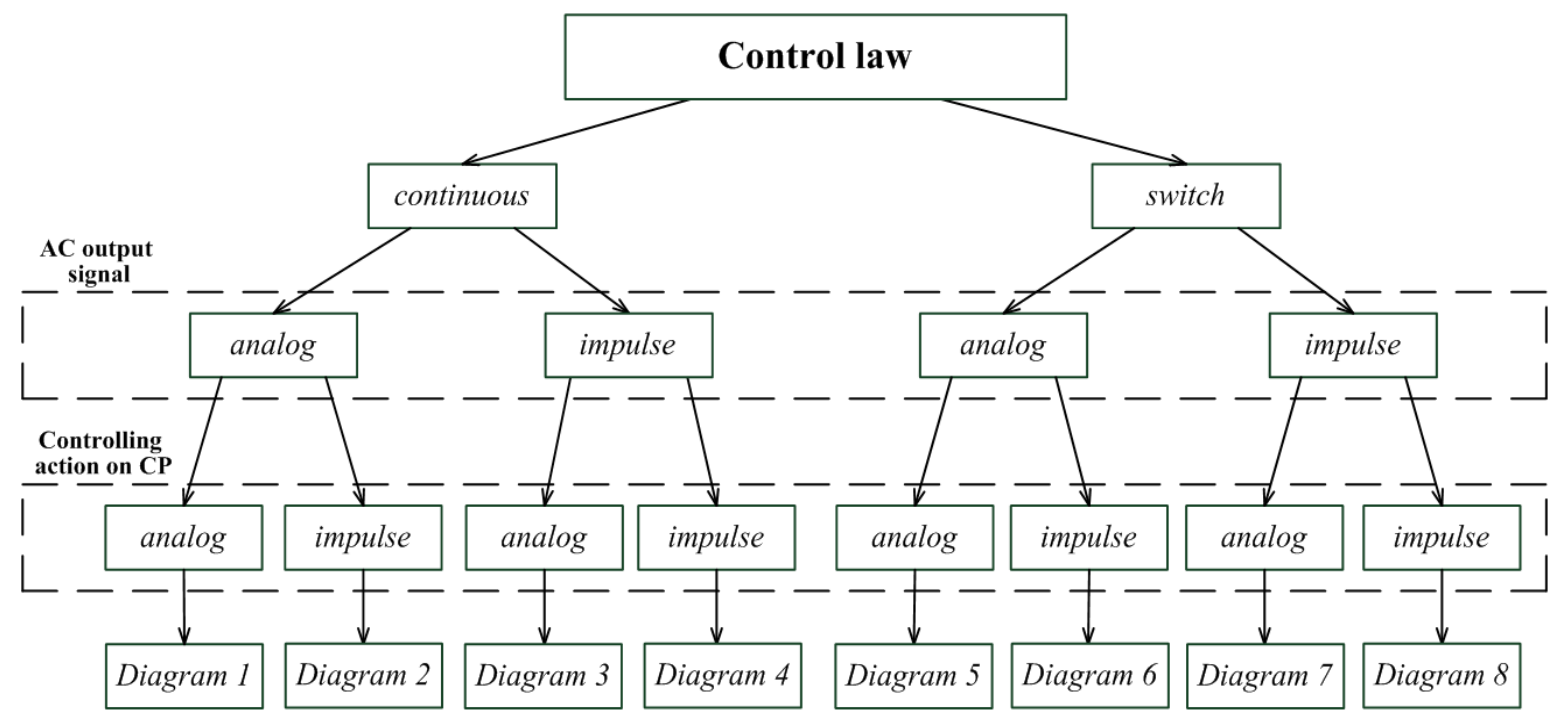

Fig. 3. New developed classification of automatic controllers diagrams with control channels

In diagram 1 according to the developed classification (see Fig. 4) the automatic controller is built on the basis of PID control law with analog output signal. This signal goes to the intermediate element in which proportional function (amplification with proportional gain coefficient $K_{P}$ ) is accomplished. The analog signal from the intermediate element is supplied to the controlled plant. In case of the thermal controlled plant the role of the intermediate element can be played by a thyristor amplifier. It increases the electric power at the input of the electric oven depending on the value of the analog output signal from the controller. 


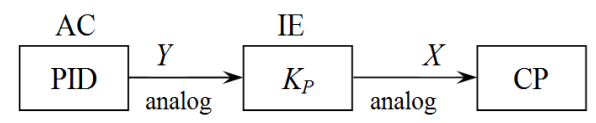

Fig. 4. Diagram 1 according to the developed classification (continuous PID controller and an amplifier)

In diagram 2 (see Fig. 5) the automatic controller like in diagram 1 is also built on the basis of PID control law with analog output signal. However, the intermediate element here is different. It consists of the pulse-width modulator (PWM) and an amplifier. The PWM impulse output signal is unipolar and it can be "ON" ("1") or "OFF" ("0"). The amplified impulse signal after the intermediate element is supplied to the controlled plant (electric oven). The amplifier here may consist of a relay or a thyristor amplifier working in the relay mode.

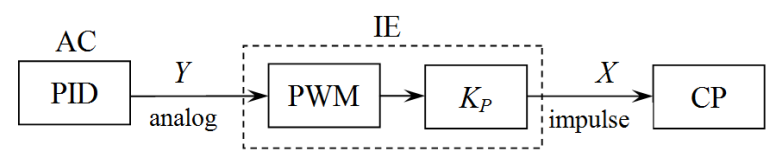

Fig. 5. Diagram 2 according to the developed classification (continuous PID controller and a pulse-width modulator with an amplifier)

In diagram 3 (see Fig. 6) the automatic controller is built on the basis of PID control law with impulse output signal. This type of the controller is called step PID controller. The purpose of the impulse signal is to control the electric actuator (motor) with constant speed of movement. The impulse output signal of the controller is bipolar and it can be "UP" ("+1"), "DOWN" ("-1") or "OFF" (" 0 "). The intermediate element in this diagram consists of the integral action actuator presented by the integral element and a valve presented by the proportional element (see Fig. 6). The intermediate element provides analog controlling action at the input of the controlled plant. In case of the thermal controlled plant the role of the valve can be played by a variable autotransformer. It provides analog change of electric power at the input of the electric oven depending on the position of the autotransformer secondary connection rotated by the actuator [5].

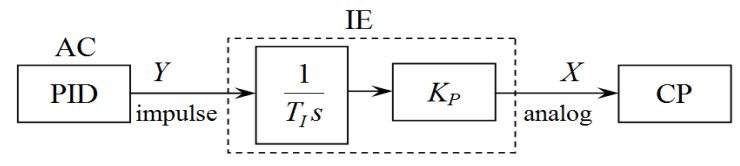

Fig. 6. Diagram 3 according to the developed classification (step PID controller and an integral action actuator with a valve)

Step PID controller for controlling the integral action electric actuator can be built on the basis of one of the following diagrams:

- $\quad$ step PID controller with double differentiation;

- continuous PID controller and a pulse-width modulator;

- continuous PID controller and a simulated positioner;

- $\quad$ step PI controller with a pulse generator.

The detailed description and analysis of step PID controllers diagrams is presented in [6]. In diagram 4 according to the developed classification (see Fig. 7) the automatic controller is built on the basis of PID control law with a pulse-width modulator (unipolar). The impulse output signal goes to the amplifier (relay). And the impulse controlling action is supplied to the controlled plant.

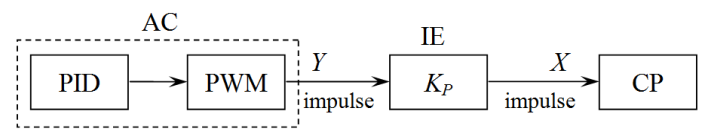

Fig. 7. Diagram 4 according to the developed classification (continuous PID controller with a pulse-width modulator and an amplifier)

In diagram 5 (see Fig. 8) the automatic controller is built on the basis of a three-point switch with an integrator. The analog output signal goes to the amplifier. And the analog controlling action is supplied to the controlled plant.

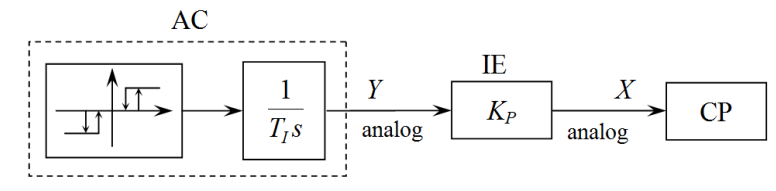

Fig. 8. Diagram 5 according to the developed classification (three-point switch with an integrator and an amplifier) 
In diagram 6 (see Fig. 9) the automatic controller like in diagram 5 is built on the basis of a three-point switch with an integrator. The analog output signal goes to the intermediate element consisting of a pulse-width modulator and an amplifier (relay). Impulse controlling action from the intermediate element is supplied to the controlled plant.

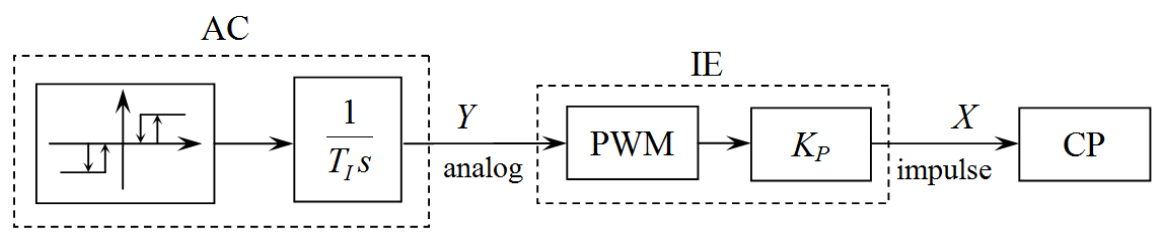

Fig. 9. Diagram 6 according to the developed classification (three-point switch with an integrator and a pulse-width modulator with an amplifier)

In diagram 7 (see Fig. 10) the automatic controller is built on the basis of a three-point switch. The impulse output signal (bipolar) goes to the intermediate element consisting of an integral action actuator presented by the integral element and a valve presented by the proportional element (see Fig. 10). Analog controlling action from the intermediate element is supplied to the controlled plant.

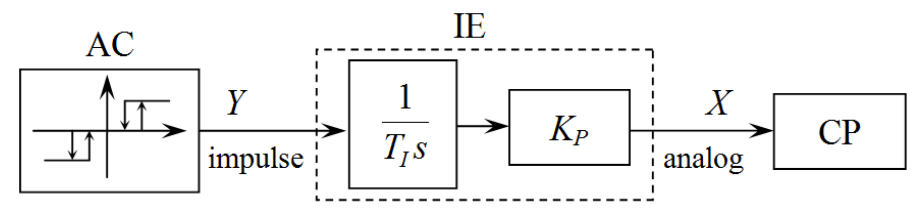

Fig. 10. Diagram 7 according to the developed classification (three-point switch and an integral action actuator with a valve)

In diagram 8 (see Fig. 11) the automatic controller is built on the basis of a two-point switch. The impulse output signal (unipolar) goes to the amplifier (relay). And the impulse controlling action is supplied to the controlled plant.

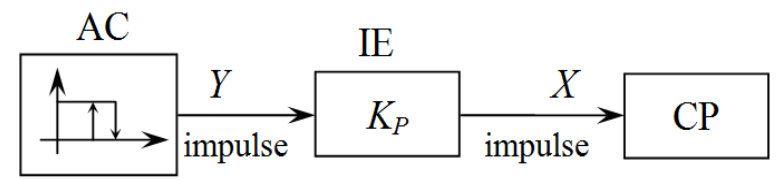

Fig. 11. Diagram 8 according to the developed classification (two-point switch and an amplifier)

The developed classification of automatic controllers diagrams with control channels is also presented in a table form (see Table 1).

\begin{tabular}{|c|c|c|c|c|}
\hline $\begin{array}{c}\text { Diagram } \\
\text { number }\end{array}$ & Control law & $\begin{array}{c}\text { AC output } \\
\text { signal }\end{array}$ & $\begin{array}{c}\text { Controlling } \\
\text { action on CP }\end{array}$ & $\begin{array}{c}\text { Intermediate } \\
\text { element }\end{array}$ \\
\hline $\begin{array}{c}\text { Diagram } \\
1\end{array}$ & $\begin{array}{c}\text { Continuous } \\
\text { (PID) }\end{array}$ & Analog & Analog & Amplifier $\left(K_{P}\right)$ \\
\hline $\begin{array}{c}\text { Diagram } \\
2\end{array}$ & $\begin{array}{c}\text { Continuous } \\
\text { (PID) }\end{array}$ & Analog & Impulse & $\begin{array}{c}\text { PWM + Amplifier } \\
\left(K_{P}, \text { relay) }\right.\end{array}$ \\
\hline $\begin{array}{c}\text { Diagram } \\
3\end{array}$ & $\begin{array}{c}\text { Continuous } \\
\text { (PID) }\end{array}$ & Impulse & Analog & $\begin{array}{c}\text { Actuator }\left(1 /\left(T_{I} \cdot s\right)\right) \\
+ \text { Valve }\left(K_{P}\right)\end{array}$ \\
\hline $\begin{array}{c}\text { Diagram } \\
4\end{array}$ & $\begin{array}{c}\text { Continuous } \\
\text { (PID + PWM) }\end{array}$ & Impulse & Impulse & $\begin{array}{c}\text { Amplifier } \\
\left(K_{P}, \text { relay) }\right)\end{array}$ \\
\hline $\begin{array}{c}\text { Diagram } \\
5\end{array}$ & $\begin{array}{c}\text { Switch (3-point } \\
\text { switch + Int.) }\end{array}$ & Analog & Analog & Amplifier $\left(K_{P}\right)$ \\
\hline $\begin{array}{c}\text { Diagram } \\
6\end{array}$ & $\begin{array}{c}\text { Switch (3-point } \\
\text { switch + Int.) }\end{array}$ & Analog & Impulse & $\begin{array}{c}\text { PWM + Amplifier } \\
\left(K_{P}, \text { relay) }\right.\end{array}$ \\
\hline $\begin{array}{c}\text { Diagram } \\
7\end{array}$ & $\begin{array}{c}\text { Switch (3-point } \\
\text { switch) }\end{array}$ & Impulse & Analog & $\begin{array}{c}\text { Actuator }\left(1 /\left(T_{I} \cdot s\right)\right) \\
+ \text { Valve }\left(K_{P}\right)\end{array}$ \\
\hline $\begin{array}{c}\text { Diagram } \\
8\end{array}$ & $\begin{array}{c}\text { Switch (2-point } \\
\text { switch) }\end{array}$ & Impulse & Impulse & $\begin{array}{c}\text { Amplifier } \\
\left(K_{P}, \text { relay) }\right.\end{array}$ \\
\hline
\end{tabular}

Table 1. Diagrams of automatic controllers with control channels according to the developed classification 
Diagram 8 is the most widespread case for controlling a thermal plant (electric oven in particular) since its adjustment and construction is simple. A shortcoming of this diagram is the self-oscillating transient process in the ACL. In order to remove the self-oscillations a PID controller with a pulse-width modulator is applied [7], i.e. diagram 2 or 4 . These diagrams provide better quality of the transient process and absence of self-oscillations. However, adjustment of these diagrams and definition of numerical values of PID control law tuning parameters is a complicated process. This problem is present not only in diagrams 2 and 4 but in all the diagrams where PID control law is applied (i.e. diagrams 1 - 4). In order to simplify this problem a special algorithm for automatic definition of numerical values of PID control law tuning parameters (PID autotune) [8] is proposed by manufacturers of PLCs.

The main principle of PID autotune algorithm work can be described in general by the following two steps. Step one: generation of self-oscillating transient process in the ACL by applying the two-point switch. Step two: definition of numerical values of PID control law tuning parameters based on the parameters of the self-oscillating transient process. It means that diagram 8 is applied during the first step. And diagram 1 is applied during the second step.

It should be mentioned that there were no diagrams 5 and 6 when the classification was developed at first. However, in order to fill the gaps in the right part of the developed classification (Fig. 3) the three-point switch with an integrator was introduced to provide an analog output signal for a switch control law. This option (diagram 5) in some cases provides even better quality of transient processes than it is done by a continuous PID controller (diagram 1). The presented diagrams of automatic controllers can be implemented in PLCs by programming.

\section{Conclusion}

The existing classifications of automatic controllers being applied in the industrial automation systems were analyzed. Based on the accomplished analysis it was defined that automatic controllers today are classified on the basis of a number of features (such as purpose of the controller, its principle of operation, construction, type of energy being used, type of controlling action and other). However, little attention is paid to putting in order and classifying the diagrams implemented in the automatic controllers. For better understanding of the distinction between the switch, continuous and step controllers as well as for understanding the place of these controllers among other controllers a new classification of automatic controllers diagrams with the control channels is proposed. All possible combinations between the types of the control law, types of the controller output signal and types of the controlling action on the controlled plant were considered in the developed classification. Conventional numbering of the automatic controllers diagrams with control channels from 1 to 8 was introduced.

The developed classification simplifies the problem of choosing and analyzing the diagrams of automatic controllers for controlling a technological process since it provides a clear demonstration of all possible ways of automatic controller action on the controlled plant with taking into account the type of control law, type of controller output signal and type of controlling action on the controlled plant.

The authors' future plans are to carry our experimental study of automatic control loop behaviour for each type of the automatic controller diagram presented in this paper and to analyze the quality of the transient processes.

\section{References}

[1] Tuning of automation instrumentation and automatic control systems: reference book / A.S. Klyuyev, A.T. Lebedev, S.A. Klyuyev, A.G. Tovarnov. - M.: Energoatomizdat, 1989. - 368 p. (Naladka sredstv avtomatizatsii i avtomaticheskih sistem regulirovaniya: spravochnoe posobie/ A.S. Klyuev, A.T. Lebedev, S.A. Klyuev, A.G. Tovarnov. - M.: Energoatomizdat, 1989. - 368 s.)

[2] Automatic control and controllers in chemical industry / Sharkov A. A., Prityko G. M., Palyukh B. V. - M.: Chemistry, 1990. - 288 p. (Avtomaticheskoe regulirovanie i regulatory v khimicheskoi promyshlennosti / Sharkov A. A., Prityko G. M., Palyukh B. V. - M.: Khimia, 1990. - 288 s.)

[3] Electronic review portal. Virtual laboratory on energy saving and energy efficiency. http://eef.misis.ru/, Accessed on: 2017-08-21.

[4] Fundamentals of automatics and automation of chemical production. Textbook for higher educational institutions. Kazakov A. V., Kulakov M. V., Melyushev Y. K. - M., "Machine-building", 1970. - 376 p. (Osnovy avtomatiki i avtomatizatsii khimicheskikh proizvodstv. Uchebnoe posobie dlya vuzov. Kazakov A. V., Kulakov M. V., Melyushev Y. K. - M., "Mashinostroenie", 1970. - 376 s.)

[5] R. Fedoryshyn, S. Klos, V. Savytskyi, O. Masniak. Identification of Controlled Plant and Development of Its Model by Means of PLC. Energy Eng. Control Syst., 2016, Vol. 2, No. 2, pp. $69 \quad-78$. https://doi.org/10.23939/jeecs2016.02.069

[6] S. Kril, R. Fedoryshyn, O. Kril, Y. Pistun. Investigation of Functional Diagrams of Step PID Controllers for Electric Actuators // Procedia Engineering, Volume 100, 2015, Pages 1338-1347. doi: 10.1016/j.proeng.2015.01.549.

[7] J.-K. Woo, D. Yang, K. Najafi, S. Lee, J. Mitchell. (2016). Miniaturized digital oven-control microsystem with high power efficiency and $\pm 1.8 \mathrm{ppm}$ frequency drift. Frequency Control Symposium, 2016 IEEE International, pp. $1-4$. DOI: 10.1109/FCS.2016.7563578.

[8] J. Korbel \& R. Prokop. Aperiodic Principle for Automatic Controller Tuning // Annals of DAAAM for 2011 \& Proceedings of the 22nd International DAAAM Symposium, Volume 22, No. 1, ISSN 1726-9679, ISBN 978-3901509-83-4, Editor B. Katalinic, Published by DAAAM International, Vienna, Austria, EU, 2011, Pages 399-400. 